\title{
Neuromodulation of Vegetative State through Spinal Cord Stimulation: Where Are We Now and Where Are We Going?
}

\author{
Giuseppe Maria Della Pepa ${ }^{a}$ Chikashi Fukaya ${ }^{b}$ Giuseppe La Rocca ${ }^{a}$ \\ Jun Zhong ${ }^{c}$ Massimiliano Visocchi ${ }^{\mathrm{a}}$

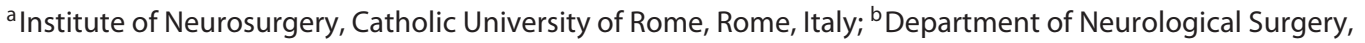 \\ Nihon University, Tokyo, Japan; ' XinHua Hospital, Shanghai Jiao Tong University, Shanghai, China
}

\author{
Key Words \\ Vegetative state - Spinal cord stimulation - Chronic \\ disorders of consciousness - Prolonged coma - Minimally \\ conscious state $\cdot$ Neuromodulation
}

\begin{abstract}
Background: Vegetative state (VS) is a complex condition that represents a challenging frontier for medicine and neuroscience research. Nowadays there is no scientifically validated treatment for VS patients, and their chronic long-term assistance is very demanding for healthcare systems worldwide. Objectives: The present paper is a systematic review of the role of spinal cord stimulation (SCS) as a treatment of patients with VS. Methods: Published literature on this topic was analyzed systematically. Clinical and epidemiological characteristics of VS, present therapeutic options and social costs of VS were also evaluated. Results: Only 10 papers have been published since 1988, and overall 308 VS patients have been treated with SCS worldwide; $51.6 \%$ displayed a clinical improvement and an amelioration of the environmental interaction. These effects are probably mediated by the stimulation of the reticular formation-thalamus-cortex pathway and by cerebral blood flow augmentation induced by SCS. Conclusions: The experience on this topic is still very limited,
\end{abstract}

and on this basis it is still hard to make any rigorous assessment. However, the most recent experiments represent significant progress in the research on this topic and display SCS as a possible therapeutic tool in the treatment of VS.

Copyright $\odot 2013$ S. Karger AG, Basel

\section{Introduction}

The healthcare management and assistance of patients with chronic disorders of consciousness, namely vegetative state (VS) and minimally conscious state (MCS), nowadays represent an issue for national healthcare assistance systems [1]. The number of patients in VS is increasing due to the increased availability of emergency care standards in the Western world. Chronic disorders of consciousness are still challenging frontiers for medicine and for neuroscience research, as much is still unclear about the pathophysiological mechanisms behind these conditions [2]. The effects of a variety of medical and surgical treatments have been described so far. As a matter of fact, there is still no treatment, either medical or surgical, that has gained the level of evidence-based treatment; with specific regard to the neuromodulation, the literature reports are fragmented and the number of ex-

\section{KARGER}

E-Mail karger@karger.com

www.karger.com/sfn (c) 2013 S. Karger AG, Basel

1011-6125/13/0915-0275\$38.00/0
G.M. Della Pepa, MD

Institute of Neurosurgery, Catholic University of Rome

Policlinico 'A.Gemelli', Largo A. Gemelli 1

IT-00168 Rome (Italy)

E-Mail gdellapepa@ hotmail.com 
periments on this topic worldwide is still very limited. Nevertheless, some results seem very encouraging [3].

Recently, a growing interest is focusing on the observation that spinal cord stimulation (SCS) can modify locoregional cerebral blood flow and determines functional changes in those brain circuits that are the neuronal substrates of consciousness and coma. The role of a 'functional' revascularization in several cerebral low-perfusion syndromes seems promising as a new trend of functional neurosurgery in cerebrovascular diseases, and SCS has been experimentally applied in challenging neurosurgical clinical fields such as cerebral ischemia and vasospasm, both on animal and human models [4]. Nevertheless, despite the promise of clinical benefit from SCS in the treatment of cerebral ischemia, its effective use has been hampered by a lack of understanding of its mechanism(s) of action.

Following the experience on neuromodulation of cerebral hemodynamic, several authors have applied SCS to VS patients with somehow encouraging and surprising evidence. The use of SCS as treatment of patients in VS is interesting as a relatively simple surgical procedure is being applied to treat patients with what has traditionally been considered a condition with a dismal prognosis and without a treatment; however, as a matter of fact, only a limited number of papers were published, literature data are fragmented and there is still no clear literature evidence on such a specific application. The data from published papers have never been collected and analyzed as a whole.

The aim of the present paper is a systematic review of the role of SCS as a treatment of patients with VS. The mechanisms of action and the limitations of treatments will be discussed.

\section{Defining the Vegetative State}

Bryan Jennett and Fred Plum coined the term 'vegetative state' in 1972 [5]. Their definition captured the essential features of the patients: 'a merely physical life, devoid of intellectual activity or social intercourse... an organic body capable of growth and development but devoid of sensation and thought'. They defined 'persistent' as presence for longer than a month [5]. Persistent VS (PVS) does not necessarily imply permanence because it is a diagnostic, not a prognostic, term. Later, others proposed the term permanent VS to refer to an irreversible VS [6].

However, before Jennet and Plum's definition, a wide range of descriptions were already used in order to identify different features of MCS, such as 'apallic state', 'aki- netic mutism', 'coma vigile', etc., often overlapping their significance with each other [2]. The lack of specific clinical criteria and the large number of slightly different definitions led to nosological confusion $[2,7]$.

Two expert task forces systematically determined the definitions of VS in the 1990s [7]. In the USA, the MultiSociety Task Force on PSV represented American neurological, neurosurgical, and pediatric neurology specialty societies, and published their report in 1994 [8]. In the UK, the Royal College of Physicians Working Group published their report in 1996 [8]. A patient is defined in VS if all of the following criteria are met: unawareness of self and environment, incapable of interaction with others, no sustained reproducible or purposeful voluntary behavioral response to visual/auditory/tactile/noxious stimuli, no language comprehension or expression, present sleep-wake cycles, preserved autonomic and hypothalamic function, bowel and bladder incontinence [9].

The diagnosis of VS and MCS can be made only after a careful assessment of the patient's level of awareness. Systematic examinations are necessary to distinguish purely reflex responses to stimuli from responses that require awareness. Confidence in this important distinction is not always possible [10].

Some patients recover to a chronic state of poor responsiveness to stimuli, but show unequivocal evidence of awareness of themselves and their environment (that is often intermittent and limited) and this condition is termed MCS [11]. There is a fundamental qualitative difference between patients in MCS and PVS: in both conditions patients are poorly responsive; however, those in MCS retain measurable evidence of awareness, whereas those in VS do not [11].

The pathology in PVS differs with each underlying cause and is variable, but usually there is significant involvement of the cortex, the subcortical white matter, and the thalamus, most consistently involving the latter two locations [9]. Over all, in spite of this existing pathologic variability, we can arbitrarily create two subgroups of patients with PVS, in which the predominant central nervous system damage is either global or multifocal $[9,10]$. These two types of pathologic groups, to a great extent, reflect the underlying causes of damage. Global ischemia and anoxia tend to produce a more diffuse 'global' type when compared to head injury, stroke, and similar afflictions, which produces multiple, but more circumscribed, 'multifocal' afflictions $[9,10]$.

The best data available on the prognosis of VS patients are from the analysis of the Task Force. At one month, $43 \%$ had regained consciousness, $34 \%$ were dead, and 
only $23 \%$ were still vegetative. The longer the VS had lasted, the fewer recovered - after six months, only $13 \%$ of those still vegetative regained consciousness [12]. It is, however, important to stress that many patients who regain consciousness after several months remain speechless and tube-fed with very limited ability to communicate and in most cases they merely show some responses that indicate a limited and fluctuating degree of awareness (thus they move to MCS) [8].

As a matter of fact, there is no defined treatment for chronic disorders of consciousness, and the actual therapeutic armamentarium has not yet gained the level of 'evidence-based treatments' [3]; these include medical interventions such as medical management by dopaminergic agents (levodopa and amantadine), zolpidem (nonbenzodiazepine-specific, indirect GABA agonist) or surgical management by deep brain stimulation (DBS), extradural cortical stimulation (ECS), SCS and intratecal baclofen (ITB) have shown to improve in some cases the level of consciousness [3].

\section{Significance for Healthcare System}

In a context of limited resources and continuous increase of healthcare expenditures, policy makers need to carefully evaluate the economic impact of prolonged medical assistance. In this particular type of context, an open issue is represented by the delicate topic of the provision of impaired conscious state assistance [13]. There is no exact figure on how many patients are in PVS in Europe or in the United States, and there is no exact figure of how much their assistance costs [13].

In 1994, the American Multi-Society Task Force estimated that in the United States the number of adults in VS is between 10,000 and 25,000 [12,14]. As these guesses are based on scaling up a small number of small studies a thousand times these estimates are not particularly robust [13]. Even if they were correct, of course, it would not be the whole story; rough calculations based on the figures given in the statement suggest that approximately $50 \%$ of PVS patients have been in that state for less than six months, $70 \%$ for less than a year [13]. Thus, on that assumption, the number of long-term PVS patients would be somewhere between 3,500 and 10,000 [15, 16].

The 1994 American Multi-Society Task Force estimated the PVS patient in a nursing facility as costing from USD 126,000 to 180,000 per year; a rough approximation of the total annual costs in the United States for the care of all adults and children in a PVS is USD 1-7 billion [15-16]. It has been estimated the average lifetime cost of care for a person in VS ranges from USD 600,000 to
$1,875,000[15,16]$. These figures may grossly underestimate the economic burden to family and society because they do not include lost earnings, costs to social service systems, and the value of the time and foregone earnings of family members who care for persons in PVS [17]. However, this study was completed nearly 20 years ago, so not only is it unclear if those demographic numbers are still valid, but almost certainly these figures cannot possibly be accurate anymore: the cost must be far greater at this point. The economic impact of the problem is enormous.

More recent figures can be, on the other hand, deduced from some European analyses where in the last years there have been some attempts to clarify and define diagnostic, prognostic, and treatment issues concerning patients with severe disturbances of consciousness. In Italy, the 2009 Healthcare Ministry Commission on chronic disorders of consciousness has estimated that the patients in VS or MCS in Italy are more than 1,500, and that this number has been increasing constantly in recent years. The cost in the acute phase has been estimated to be roughly EUR 516 per day, up to a cost of EUR 155,000 for the first year of assistance [18]. Afterwards the cost is reduced to basic medical and nursing assistance to EUR 186 per day for overall EUR 67,100 per year [18]. Such figures do not significantly differ from other European countries such as France, Germany or the United Kingdom [19-21].

A recent study on the French population in the Maineet-Loire county specifically analyzed VS patient management, physical complications, problems encountered by nursing and medical staff [20]. The most common problem among these patients was spastic hypertonia in flexion and adduction; the orthopedic deformities caused by spasticity impacted on hygiene and nursing care in all cases and the medical staff considered that care was extremely difficult. One other organizational difficulty was personal care and dressing that, in this survey, on average lasted 30 minutes and required two caregivers. Almost all the VS patients had required gastrostomy for feeding; it was extremely difficult to organize bed transfers and transfers to a wheelchair, and nearly one half of patients were permanently confined to bed, while other patients were, on average, transferred to the sitting position three to seven times per week, for an average of $2-6 \mathrm{~h}$ at a time [20].

It is of interest that a high mortality during the first year is reported, with a mean survival of only $2-5$ years for patients in VS at one month [22]. What is of more interest, however, is the expectation of life for those who 
Table 1. Vegetative state: an overview

\begin{tabular}{|c|c|}
\hline Epidemiology & $\begin{array}{l}\text { Prevalence: nearly } 19 \text { per million } \\
\text { (2001 estimation) } \\
\text { At least } 10,000-25,000 \text { adults and } 6,000-10,000 \\
\text { children are in VS in the USA }\end{array}$ \\
\hline Length of VS & $\begin{array}{l}50 \% \text { of PVS patients are in that state for less than } \\
6 \text { months, } 70 \% \text { for less than } 1 \text { year } \\
\text { Overall mean survival: } 2-5 \text { years } \\
\text { Mean survival for young adult vegetative after } \\
1 \text { year: } 10.5 \text { more years (median } 5.2 \text { years) } \\
\text { Mean survival in PVS } 4 \text { years after the insult: } \\
12.2 \text { (median } 7 \text { years) } \\
\text { Occasional survivals of } 20 \text { or more years }\end{array}$ \\
\hline Etiology & $\begin{array}{l}\text { Adults: traumatic brain injury (the most } \\
\text { common cause), nontraumatic causes in adults: } \\
\text { acute hypoxic-ischemic neuronal injury (during } \\
\text { cardiopulmonary arrest), stroke, and } \\
\text { meningoencephalitis } \\
\text { Children: trauma, meningitis, asphyxia, } \\
\text { congenital malformations, and perinatal injuries }\end{array}$ \\
\hline Brain lesion & $\begin{array}{l}\text { Marked atrophy, bihemispheric lesions, } \\
\text { thalamoreticular pathway damage, brainstem } \\
\text { focal lesions }\end{array}$ \\
\hline Costs & $\begin{array}{l}\text { US: USD 126,000-180,000/year; total annual } \\
\text { costs (adults and children) USD } 1-7 \text { billion } \\
\text { Europe (Italy): acute phase EUR 516/day; } \\
\text { EUR } 155,000 \text { for the first year of assistance } \\
\text { Afterwards EUR 186/day, EUR } 67,100 / \text { year } \\
\text { Average lifetime cost from USD } 600,000 \text { to } \\
\text { USD 1,875,000 }\end{array}$ \\
\hline Therapy & $\begin{array}{l}\text { Nonsurgical: dopaminergic agents (levodopa and } \\
\text { amantadine), zolpidem (nonbenzodiazepine- } \\
\text { specific, indirect GABA agonist) } \\
\text { Surgical: deep brain stimulation (DBS), } \\
\text { extradural cortical stimulation (ECS), spinal cord } \\
\text { stimulation (SCS), intratecal baclofen (ITB) }\end{array}$ \\
\hline
\end{tabular}

have already survived in a vegetative state for a year or more. The continuing annual mortality then reduces year by year, and there have been occasional survivals of 20 or more years [22]. A systematic study in California drew attention to the difference between mean and median survival, the latter being shorter because not distorted by the occasional very long survival [23]. For a young adult vegetative after one year, this study calculated a mean survival of 10.5 more years, the median being 5.2 years [ $22-$ 23]. For one still vegetative four years after the insult, these figures increase to 12.2 and 7 more years, respectively [22-23].

An overview of VS characteristics is summarized in table 1.

\section{Methods}

Searches were performed in the Medline databases using the following key words: 'vegetative state', 'minimally conscious', 'disorders of consciousness', 'coma', 'effect', 'therapy', 'recovery' along with 'neuromodulation' 'spinal cord stimulation', 'SCS', 'dorsal column stimulation', and 'cervical stimulation'. The electronic search was complemented by cross-checking the references of all relevant articles. Only papers dealing with subjects with a diagnosis of PVS were included in the research. All other diagnoses of chronic disorders of consciousness were thus discharged. Special attention was paid to identify the patients which have been described in more than one publication (for example follow-up of already published studies) in order to avoid duplications.

\section{Results}

We found 10 reports (patient series or single-patient reports) matching the research criteria. Some of these were published in the Japanese language and only the abstracts were available in English: these articles were specifically analyzed by one of the authors of the paper, a Japanese neurosurgeon. Results from the literature review are summarized in table 2 . Overall 308 patients in VS were treated by SCS from 1988; a clinical response was reported in 159 patients (51.6\%) with amelioration of neurological function and arousal; some papers depict brilliant responses to stimulation.

Patients were assessed either clinically, with neuroimaging (RMN, CT), cerebrospinal fluid (CSF) metabolites assessment, neurophysiological studies [EEG, auditory brainstem response (ABR), SEP], or brain metabolism investigations [single photon emitting computed tomography (SPECT), Xe-CT]. The patients that were included in the published papers were VS secondary to trauma, anoxia or stroke. In all the papers the SCS device was implanted into the epidural space between $\mathrm{C} 2$ and C4, stimulating the spinal cord in a cyclic mode of $15 \mathrm{~min}$ on and 15 min off only during daytime, without reaching the motor threshold (amplitude ranging from 2 to $15 \mathrm{~V}$; frequency from 25 to $200 \mathrm{~Hz}$; pulse width from 0.3 to $1.0 \mathrm{~ms}$ ). Stimulation was administered from 2 to $11 \mathrm{~h} /$ day.

Average clinical improvement latency was quite variable, ranging from 3 days to 1 year after initiation of the stimulation, and in some cases it was observed after less than 1 day of stimulation. Clinical response was better in patients in VS for little time compared with patients who were in VS for longer time; younger patients have a better response compared to older ones [24]. CT/MRI findings in the cases which had been treated effectively showed no marked cerebral atrophy, and no bilateral large diffuse low-density areas not involving the thalamus nor any def- 


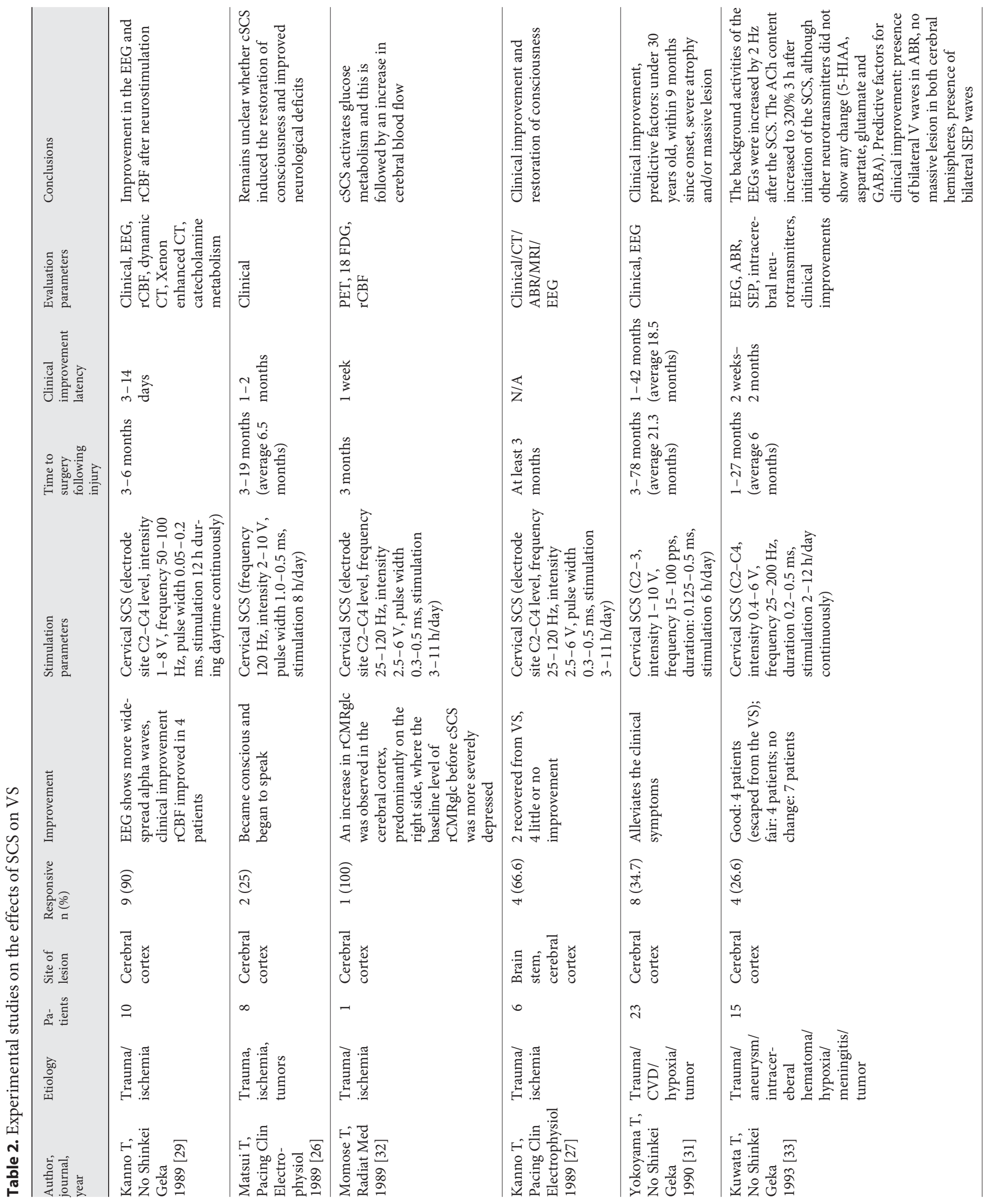




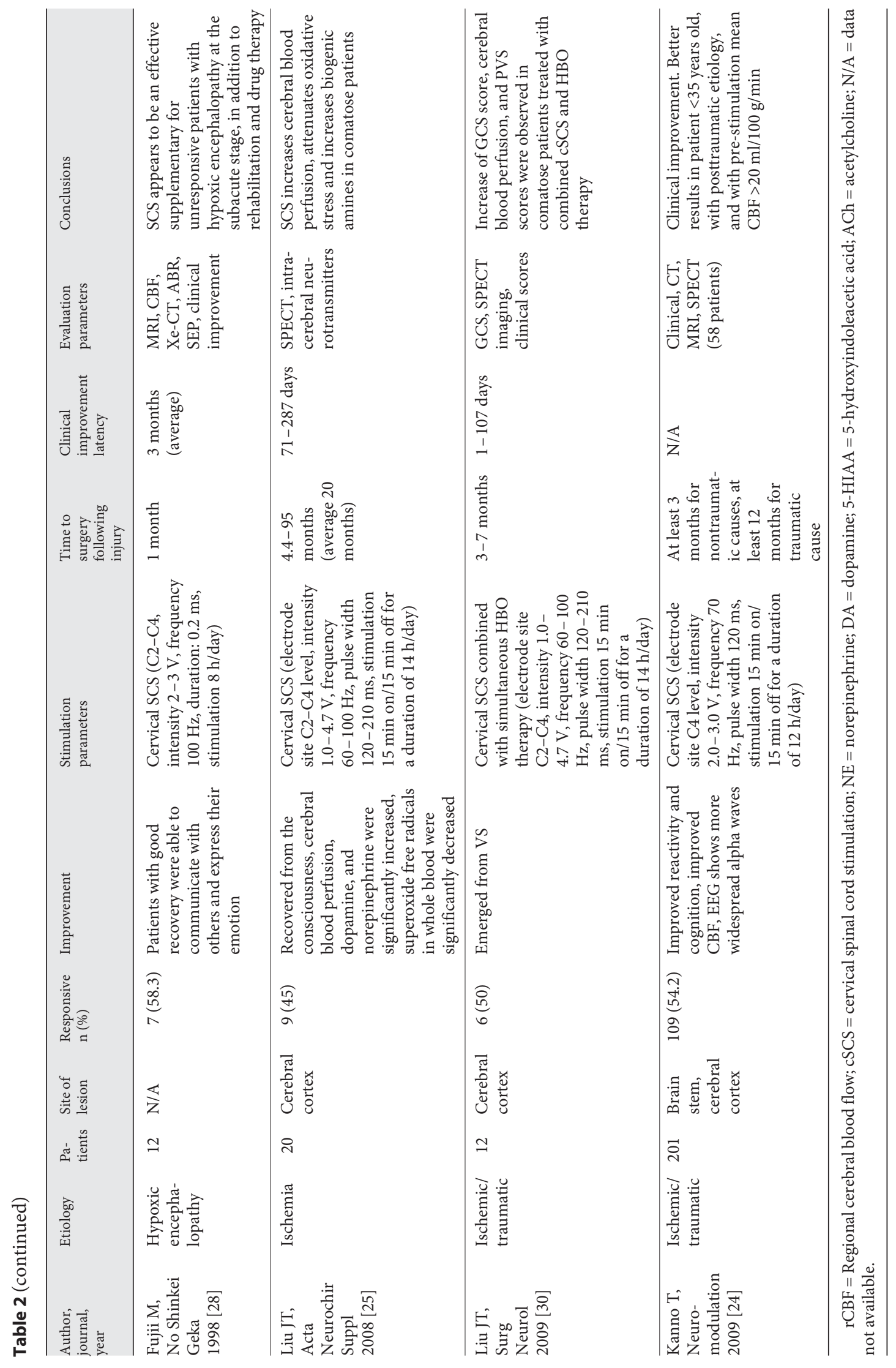


Table 3. Pre-stimulation variables related with better response after SCS

\begin{tabular}{ll}
\hline Age & Younger patients display generally better results \\
\hline Length of & $\begin{array}{l}\text { Patients with recent VS have better chances of } \\
\text { improvement after stimulation compared with } \\
\text { patients in VS for a longer period of time; however, } \\
\text { results are also observed in patients in VS for a long } \\
\text { time (problem of differentiating a spontaneous } \\
\text { recovery from a SCS-induced recovery in those with } \\
\text { recent VS) }\end{array}$ \\
\hline Etiology & $\begin{array}{l}\text { Traumatic etiologies (also associated to } \\
\text { posttraumatic hemorrhage) display better response } \\
\text { compared to hypoxic VS }\end{array}$ \\
\hline Brain & $\begin{array}{l}\text { Absence at CT/MRI of marked atrophy, } \\
\text { lesion }\end{array}$ \\
$\begin{array}{l}\text { bihemispheric lesions, thalamoreticular pathway } \\
\text { clinical response }\end{array}$ \\
\hline $\begin{array}{l}\text { Electro- } \\
\text { physiology } \\
\text { the forebrain (such as presence of bilateral V waves } \\
\text { in ABR, presence of bilateral SEP waves, continuous } \\
\text { EEG monitoring) }\end{array}$ \\
\hline $\begin{array}{l}\text { Sustained mean hemispheric blood flow bilaterally } \\
\text { (CBF }>5 \text { ml/100 g/min bilaterally) is related with } \\
\text { better outcome }\end{array}$ \\
\hline CBF & \\
\hline &
\end{tabular}

inite and large low-density areas in the brainstem. Traumatic etiologies (also associated to posttraumatic hemorrhage) display better response compared to hypoxic etiologies [24]. In those cases in which cerebral blood flow (CBF) was assessed it was established that better response was achieved in those subjects who maintained a sustained mean hemispheric blood flow bilaterally (CBF that exceeded 20-25 ml/100 g/min) [24]. Increase of cerebral blood perfusion and catecholamines (dopamine and norepinephrine) in CSF after SCS has been observed, whereas epinephrine level was unchanged [25]. The superoxide free radicals were decreased after SCS [25].

Table 3 shows the pre-stimulation variables related with a significant response after SCS and table 4 reviews the specific findings observed after stimulations.

\section{Discussion}

\section{The Magnitude of Improvement}

The first consideration that rises up from our review is that the experience on this topic is still very limited. From 1989 to now only 10 papers (including patient series or
Table 4. Findings during SCS

\begin{tabular}{|c|c|}
\hline Age & $\begin{array}{l}\text { Younger patients display generally better } \\
\text { results }\end{array}$ \\
\hline $\begin{array}{l}\text { Stimulation } \\
\text { parameters }\end{array}$ & $\begin{array}{l}\text { Electrode site: } \mathrm{C} 2 \text { and } \mathrm{C} 4 \text {, cyclic mode ( } 15 \\
\text { min on/ } 15 \text { min off) during daytime, } \\
\text { amplitude ranging from } 2 \text { to } 15 \mathrm{~V}(2 / 3 \text { the } \\
\text { motor threshold; } 25-200 \mathrm{~Hz} \text {; pulse width } \\
0.3-1.0 \mathrm{~ms}) \text {; variable hours/day. The one } \\
\text { associated with the best results (Kanno } \\
\text { 1988: } 90 \% \text { success rate): electrode site C2, } \\
\text { stimulation } 12 \mathrm{~h} \text { /day }\end{array}$ \\
\hline Clinical response & 159 out of the 308 patients (51.6\%) \\
\hline $\begin{array}{l}\text { Average clinical } \\
\text { improvement } \\
\text { latency }\end{array}$ & $\begin{array}{l}\text { From } 3 \text { days to } 1 \text { year after the beginning of } \\
\text { the stimulation, in some cases less than } \\
1 \text { day of stimulation }\end{array}$ \\
\hline $\mathrm{CBF}$ & Increased when measured \\
\hline $\begin{array}{l}\text { Other parameters } \\
\text { improved }\end{array}$ & $\begin{array}{l}\text { Neuroradiological: PET, } 18 \text { FDG, Xe-CT, } \\
\text { MRI, CT } \\
\text { Neurophysiological: EEG, ABR, AEP, SEP } \\
\text { Neurochemical: CSF metabolism (5-HIAA, } \\
\text { aspartate, glutamate and GABA, NE, DA) }\end{array}$ \\
\hline
\end{tabular}

FDG = Fludeoxyglucose; 5-HIAA = 5-hydroxyindoleacetic acid $\mathrm{NE}=$ norepinephrine; $\mathrm{DA}=$ dopamine.

single case reports) have been published which specifically concern the effects of SCS on VS, and many of these (almost half) were published in the Japanese language. In most cases it was hard to clearly identify the magnitude of 'clinical' improvement, especially in the oldest papers, and in many cases some observations sound overenthusiastic and not scientifically rigorous.

One other important constraint concerns the definition of terms: VS has been distinguished from other chronic disorders of consciousness only after Jennett and Plum's definition in 1972 [5], and only in the 1990s were definition criteria systematized [7, 8]. Many of the papers included in the review were published before the 1990s; thus, the definition of VS in various papers reviewed (especially older ones) did not always use the same metrics. Thus, particular attention was focused to include in the review process only articles that were clearly indicating VS patients (even if using different nosological definitions such as coma vigile, apallic state, etc.) according to modern definition criteria of VS.

However, despite these criticisms, it must be noted that there are some very promising and detailed findings, especially in the most recent publications, which high- 
light that cervical SCS could actually play a significant role in the treatment of chronic disorders of consciousness.

From our analysis, a clinical response is observed in more than half of the treated subjects. It is important to discuss the magnitude of clinical response: the early overenthusiastic reports describe cases of restoration of interaction, ability to speak and to interact [26-29]. Probably in such cases, either the initial clinical condition was misdiagnosed or some results were reported in an exceedingly eager fashion. More realistically, the extent of the clinical response is limited to amelioration of the arousal and in some case of the interaction with the environment.

On the other hand, also the most recent publications (with larger series, more reliable outcome evaluation parameters, and longer permanence in VS before stimulation) confirmed that a relevant number of subjects in PVS improved after stimulation [24, 25, 30]. These studies were also more selective in patient selection criteria (in all cases, VS duration was longer than 3 months for hypoxic etiologies and at least one year for traumatic etiologies). In such a more rigorous setting, after stimulation about half of the patients displayed features not observed before (such as behavioral expression, swallowing when food or water is placed in the mouth, speaking meaningful words and displaying some emotional response) [24]. In some cases, such an improvement was evident already a few days after the beginning of stimulation $[25,30]$.

A limitation of the majority of the relevant studies includes the heterogeneity of patients' characteristics and of their brain injuries (location, distribution and duration) and the natural history related with it. Thus, it is impossible to differentiate a spontaneous recovery from a SCSinduced recovery. Such a generalization of the reported results makes it hard to understand which patients might respond to stimulation. Marked variation in patterns of structural brain damage underlying severe disability will require development of structured assessments of the integrity of cerebral systems to ultimately determine a likelihood of response to SCS, rather than a diagnostic classification based on behavioral assessments (either qualitative or quantitative).

Given that the effect of SCS is difficult to distinguish from spontaneous recovery, the recovery rate was more than half in treated patients after stimulation, and such a figure can still be considered relevant. Such an improvement can be observed in a relevant number of cases also in those studies in which patients were in VS for a considerably long period $[24,25]$. Conversely, figures dealing with spontaneous recovery after 6 months from the acute event drop down to $13 \%$ and further decrease afterwards [11]. In addition, the timeline generally shows a linear trend beginning at onset of the testing and that carry-over effects are present immediately and continue to grow roughly linearly. In addition, clinical/electrophysiological effects can be observed also after turning off the stimulator.

This trend is particularly evident in the 2008 study by Liu et al. [25] that experimented with SCS for a prolonged time (up to 287 days consecutively) and in the 1990 study published by Yokoyama et al. [31] who experimented with SCS up to a period of consecutive 42 months. The presence of slow ongoing carry-over effects is definitely important in the interpretation of the impact of SCS in VS patients. These observations collectively provide unequivocal evidence of both reproducible acute effects of SCS as well as more enduring and slowly accumulating effects. Such evidence, however, adds a very significant further challenge to the design of future studies and an additional caveat for the interpretation of earlier studies that lacked blocked-off periods or formal behavioral assessments. Not only do immediate arousal effects not predict future behavioral improvements but linear improvements in function may be due to either SCS or rehabilitation or time. Only rigorous study design and data analysis can distinguish the potentially separate contributions of each of these variables.

Under the neurophysiological, metabolic and hemodynamic point of view, it was observed that neurostimulation enhances neurophysiological (SEP and ABR) and EEG patterns, improves the metabolism of catecholamines in CSF and can produce a global amelioration of cerebral perfusion, and these findings are strictly related to clinical response $[4,24,25,32]$. These results suggest that SCS increases cerebral blood perfusion, attenuates oxidative stress and increases biogenic amines in VS patients [25]. Liu et al. in 2009 [30] reported good results in simultaneous SCS and hyperbaric oxygen therapy (HBO), thus confirming the role of $\mathrm{CBF}$ in modulating such effects (see table 4).

\section{Patient Selection}

In acknowledgement of the above mentioned limitations, we could observe that variables such as patient age and length of VS are related to better clinical effects. In their paper published, respectively, in 1993 and 1990, Kuwata [33] and Yokoyama et al. [31] documented how stimulation started earlier brought more significant results compared with patients that had been in VS for a longer period of time (stimulation initiated in the first 3 
months in ischemic etiology, and within the first year for traumatic etiology, brought more consistent results). This observation, along with the fact that younger patients display better clinical responses [24, 25, 31], probably reflects the natural history related with VS, thus making it hard to effectively discriminate the real burden of SCS on recovery from the natural course.

Anyway, the integrity of specific brain circuits and their likelihood to respond to stimulation (absence of large bihemispheric damage, integrity of thalamoreticular pathways, absence of brainstem focal damages, and sustained mean hemispheric blood flow and metabolism bilaterally) seem crucial [24]. Hence again, patient selection should not be merely based on clinical syndromic criteria but might best be tailored on the basis of an assessment of integrity of large-scale circuits within the forebrain (see table 3). In this perspective, pre-stimulation electrophysiological testing might possibly determine those potentially most promising candidates. In the analyzed literature, ABR was used for evaluation of brainstem function $[27,28,33]$ and somatosensory evoked potentials for evaluation of thalamocortical function bilaterally [28, 33]; some other authors carried out continuous EEG frequency analysis to determine the relationship between the brainstem and the cerebral cortex [31].

In fact, anatomical findings of CT or magnetic resonance imaging are useful for evaluating resting brain function when brain damage is very severe such as bilateral diffuse injury of the thalamus or cerebral cortex; however, such anatomical data are usually insufficient for evaluating resting brain function correctly and deciding the effectiveness of SCS therapy for certain patients, while electrophysiological testing might better depict the situation of functional damage.

One other important parameter is the assessment of $\mathrm{CBF}$ in the selection of candidates, as it is a useful parameter for indirectly estimating the residual brain function. In particular, a residual CBF greater than $25 \mathrm{ml} / 100 \mathrm{~g} /$ min bilaterally has been observed to be related with better outcome [28, 32]; however, we must be cognizant of the fact that $\mathrm{CBF}$ at the chronic stage does not always represent the severity of acute brain anoxia [34].

\section{Impact on Care}

It is hard to estimate how these responses can ameliorate patient care, and this still remains an open question. It is debatable whether an improvement of the patient arousal level can drive to direct improvements in terms of chronic care. Unfortunately, none of the analyzed articles consider impact on the patients' chronic care in terms of marginal costs. However, despite that, the aspects of communication and reintegration are nevertheless important goals from a medical and ethical point of view, and caregivers and family members place restoration of functional communication as the first goal of care.

Moreover, it must be admitted that an increase in patient collaboration could improve problems related to personal care and dressing; an improved collaboration, along with the demonstrated effect of SCS in reducing spasticity $[35,36]$, might substantially help hygiene and nursing care and reduce orthopedic deformities. These problems were considered by a French survey that analyzed patient management, physical complications, and problems encountered by nursing staff as some of the most critical issues in their chronic care [20]. In this study, some other significant concerns in chronic care were bed transfers and transfers to a wheelchair [20]. One other aspect that can be taken into consideration is feeding; from our review, a relevant number of treated patients were able to return to an oral feeding after stimulation. An improved collaboration along with a reduced spasticity might impact on the number of caregivers required for daily activity such as feeding and hygiene, and reduce the number of patients permanently confined to bed.

\section{Speculating on Possible Mechanisms}

Experimental research aimed at understanding the pathophysiology underlying long-term comatose states have provided insights into the central nervous system (CNS) functions of affected patients. Some patients whose original injury was global in nature (such as anoxia) show widespread, significant neuronal loss, and this may be one reason why PVS due to nontraumatic injury is less likely to improve than long-term coma after trauma $[5,7]$. Laureys et al. $[37,38]$ noted that many patients with PVS have a combination of neuronal loss and dysfunction of surviving neurons. Overall cerebral metabolism of glucose may be decreased $50-65 \%$, but the pattern is not homogeneous. Their model postulates that loss of consciousness is as much functional as anatomical. Of outstanding clinical value is their final observation: patients who regain consciousness move through a series of clinical improvements beginning with appearance of sustained visual pursuit; clinical improvement occurs in parallel with imaging changes supporting reconnections of corticothalamiccortical associations $[37,38]$. Other authors have termed the concept of viable but inactive neurons that can be stimulated into recovery as the idling neurons hypothesis [39]. Consideration of this general model of PVS corre- 
lates with research findings and resulting hypotheses regarding mechanisms underlying the efficacy of SCS as facilitator of recovery after brain injury $[25,30]$.

Stimulation of the Reticular

Formation-Thalamus-Cortex Pathway

The concept of the ascending arousal system has been accepted for more than half a century as the basis for understanding the neuronal substrates of consciousness and coma. This model has directed and shaped research on cortical function and sleep-wake regulation, as well as clinical evaluation of patients with loss of consciousness [40]. The projections from the reticular formation to the central thalamus to the cerebral cortex may constitute a critical pathway for maintaining a waking cortical state [41]. Cervical SCS might enhance this specific firing to the cerebral cortex by a direct effect on the reticular formation [42].

Presumably, sufficient firing may be present in most of these patients when electrically stimulated [43]. In fact, theoretical models demonstrate that merely the connectivity of linked cortical pyramidal output neurons, reticular thalamic and thalamic relay neurons are sufficient to generate the variety of patterns [44]. Consistently with this minimal requirement of underlying substrate, SCS could interfere with corticothalamic circuits (with preservation of desynchronized responses to modulatory 'arousal systems'), and with reticulo-corticothalamic excitatory neurotransmission. The introduction of an artificial excitatory drive to the neocortical and striatal neurons connected with the reticular formation is likely to have significant network impact, based on their broad connectivity [45]. Studies in primates demonstrated enhancement of behavioral performance in a sensorymotor task following stimulation of the neurons in the mesencephalic reticular formation, which, as noted above, strongly innervates the central thalamus [46].

\section{CBF Improvement}

In those case in which CBF was assessed it was established that better response was achieved in those subjects who maintained a sustained mean hemispheric blood flow bilaterally (CBF that exceeded $25 \mathrm{ml} / 100 \mathrm{~g} / \mathrm{min}$ ). Moreover in all the PVS-improved patients CBF was improved as well. Consequently $\mathrm{CBF}$ is crucial in understanding the SCS-induced effect in PVS.

SCS has been shown to augment CBF and speculated to protect the brain from focal ischemia in a large series of experiments, both on animals and on humans [47-53], and has been proposed for the treatment of several cere- bral low-perfusion syndromes [54-67]. However, there is not yet an ultimate scientific explanation; moreover, a clear understanding of the mechanisms elicited by SCS is still lacking $[4,53,68]$. Different hypotheses have been reported in the literature so far. From the updated literature review, more than a single mechanism seems to be responsible for SCS-induced amelioration in VS $[4,48]$. $\mathrm{CBF}$ amelioration observed in both experimental and clinical data support the idea that the autonomic nervous system might be the major mechanism elicited by cervical SCS, although recent studies underline how the release of local humoral factors by cerebral vasculature might also play a significant role in determining SCS effects on cerebral hemodynamics [4]. The major experiments related with CBF enhancement in humans after SCS are summarized in table 5.

A reduction of sympathetic outflow during SCS has been demonstrated by a series of studies. This so-called 'reversible functional sympathectomy' can, at least partially, account as one of the possible mechanisms put in play by SCS to produce such effects on cerebral hemodynamic [47, 50, 69]. Myklebust et al. [70] found norepinephrine levels markedly affected during SCS, confirming a sympathetic inactivation secondary to neurostimulation. Several papers analyzed how spinal cord integrity deals with the SCS interferences on CBF $[4,51]$. The most significant experiments have been published by Isono and Patel. Isono et al. [71] observed that the ability of SCS to increase $\mathrm{CBF}$ is peculiar to high cervical cord stimulation with moderately low frequencies and that no hemodynamic effects occur during SCS when the dorsal columns are sectioned at the medullocervical junction, confirming the role of specific spinal cord pathways in determining the increase of CBF during SCS [49]. Patel et al. [72, 73] reported that SCS-induced changes in CBF were completely attenuated by spinalization, suggesting that the mechanisms underlying the effects of SCS involve central influences rather than cervical sympathetic outflow [61].

Hosobuchi $[74,75]$, in his pioneer observations in humans, had already noticed a persistent elevation of CBF also after interruption of the stimulation. He suggested that this phenomenon could be explained by the involvement of humoral factors. In particular he observed that indomethacin was able to partially block the effect of SCS on CBF, while atropine did not affect the results $[74,75]$. Other possible factors proposed include substance $\mathrm{P}(\mathrm{SP})$, vasoactive intestinal polypeptide (VIP) and calcitonin gene-related peptide (CGRP) [4, 76-79]. Such findings could explain the long-lasting response induced by SCS in VS also after turning off the stimulator. 
Table 5. Major experimental and clinical studies on humans investigating the SCS effects on CBF

\begin{tabular}{|c|c|c|c|}
\hline First author, year & Observation method & Site of stimulating electrode & Hemodynamic findings \\
\hline Hosobuchi, 1985 [75] & SPECT (Xe 133) & Cervical/thoracic & $\begin{array}{l}\text { Indomethacin blocks CBF effects; atropine } \\
\text { does not affect CBF effects; increase in CBF } \\
\text { in cerebral ischemia }\end{array}$ \\
\hline Meglio, 1986 [81] & TCD, SPECT & Cervical/thoracic & $\begin{array}{l}\text { Functional sympathectomy during SCS } \\
\text { (para-sympathetic activation and blockade) }\end{array}$ \\
\hline Hosobuchi, 1991 [74] & SPECT & Cervical & Increase in $\mathrm{CBF}$ in cerebral ischemia \\
\hline Visocchi, 1994 [49] & $\begin{array}{l}\text { NIRS; surface } \\
\text { polyelectromyography; TCD }\end{array}$ & Cervical & $\begin{array}{l}\text { Clinical, neurophysiological improvement in } \\
\text { cerebral ischemia }\end{array}$ \\
\hline Mazzone, 1995 [69] & $\begin{array}{l}\text { SEP, xenon computed } \\
\text { tomography }\end{array}$ & Cervical & $\begin{array}{l}\text { Amelioration of both SEP and CBF, in } \\
\text { different patients despite etiology }\end{array}$ \\
\hline Visocchi, 1996 [82] & TCD & Cervical & $\begin{array}{l}\text { SCS and } \mathrm{CO}_{2} \text { interact with mechanisms of } \\
\text { regulation of CBF in a competitive way }\end{array}$ \\
\hline Takanashi, 2000 [61] & $\begin{array}{l}\text { Xenon computed tomography } \\
\text { and cerebral angiography }\end{array}$ & Cervical & $\begin{array}{l}\text { Clinical and CBF improvement in patients } \\
\text { with cerebral vasospasm (SAH patients } \mathrm{HH} \\
2-3 \text {, Fisher } 3 \text { ) }\end{array}$ \\
\hline De Andrés 2007 [53] & Doppler, functional MRI & Cervical & $\begin{array}{l}\text { Clinical improvement and increase in } \mathrm{CBF} \text { in } \\
\text { cerebral ischemia }\end{array}$ \\
\hline $\begin{array}{l}\text { Clavo, 2002, 2003, 2004, } \\
2006,2007,2009,2012 \\
{[55-57,59,60,62,65]}\end{array}$ & TCD, polarographic probes & Cervical & $\begin{array}{l}\text { In patient with gliomas increased tumour } \\
\text { perfusion and oxygenation }\end{array}$ \\
\hline
\end{tabular}

$\mathrm{NE}=$ Norepinephrine; $\mathrm{TCD}=$ transcranial Doppler sonography; $\mathrm{SEP}=$ somatosensory evoked potentials. $\mathrm{HH}=\mathrm{Hunt}-\mathrm{Hess}$ grading for sub-arachnoid hemorrhage.

\section{Conclusions}

PVS is not a well determined clinical condition regarding its natural history; the literature concerning the effect of SCS on PVS is still very limited and fragmented: few papers have been published in recent years and most of them not in world-wide spoken languages, reporting limited series of patients or often single overenthusiastic case reports. On such bases it is hard to make any assessment that would be scientifically rigorous. However, some experiments, especially the most recent ones, represent a significant progress in the research on this specific topic $[25,30]$.

PVS is an expensive disease both in economic and social terms. Neurophysiological evidence supports the hypothesis that SCS can really induce some clinical improvement in patients with chronic disorders of consciousness by stimulation of the of the reticular formation-thalamus-cortex pathway with effects associated to $\mathrm{CBF}$ and metabolism augmentation $[4,47]$. The chapter of neuromodulation in chronic disorders of consciousness has historically been a fervent field of debate $[3,30,80]$. Although DBS, extradural cortical stimulation, and intratecal baclofen have also been proposed as a treatment for VS patients [3]. Nevertheless, SCS is a more feasible procedure, less expensive, less risky, easier to manage postoperatively and can be performed also in non-neurosurgical operating theaters $[4,68]$. Moreover, many of these patients could benefit from SCS anyway, for spasticity, bowel and bladder dysfunctions that are frequently related with PVS [4]. Consequently, the relative feasibility of SCS, compared with other techniques, should encourage further prospective multicentric studies in order to (1) identify the best candidates on the basis of the most reliable clinical, morphological, biochemical and neurophysiological indicators of a potential response; (2) definitively assess the clinical effects of SCS in PVS, and (3) define economic advantages of SCS in terms of care management. 


\section{References}

1 Oliveira L, Fregni F: Pharmacological and electrical stimulation in chronic disorders of consciousness: new insights and future directions. Brain Inj 2011;25:315-327.

$\checkmark 2$ Bruno MA, Vanhaudenhuyse A, Thibaut A, Moonen G, Laureys S: From unresponsive wakefulness to minimally conscious PLUS and functional locked-in syndromes: recent advances in our understanding of disorders of consciousness. J Neurol 2011;258:1373-1384.

>3 Georgiopoulos M, Katsakiori P, Kefalopoulou Z, Ellul J, Chroni E, Constantoyannis C: Vegetative state and minimally conscious state: a review of the therapeutic interventions. Stereotact Funct Neurosurg 2010;88: 199-207.

4 Visocchi M, Della Pepa GM, Esposito G, Tufo T, Zhang W, Li S, Zhong J: Spinal cord stimulation and cerebral hemodynamics: updated mechanism and therapeutic implications. Stereotact Funct Neurosurg 2011;89:263274 .

5 Jennett B, Plum F: Persistent vegetative state after brain damage. A syndrome in search of a name. Lancet 1972;1:734-737.

6 Borthwick CJ: The permanent vegetative state: ethical crux, medical fiction? Issues Law Med 1996;12:167-185

7 Jennett B: Thirty years of the vegetative state: clinical, ethical and legal problems. Prog Brain Res 2005;150:537-543.

8 Jennett B: The persistent vegetative state. Task force's definition influences interpretation of outcome. BMJ 1995;310:1137.

19 Bernat JL: The natural history of chronic disorders of consciousness. Neurology 2010;75: 206-207.

10 Bernat JL: Chronic consciousness disorders. Annu Rev Med 2009;60:381-392.

11 Giacino JT, Ashwal S, Childs N, Cranford R, Jennett B, Katz DI, Kelly JP, Rosenberg JH, Whyte J, Zafonte RD, Zasler ND: The minimally conscious state: definition and diagnostic criteria. Neurology 2002;58:349-353.

12 Medical aspects of the persistent vegetative state (1). The Multi-Society Task Force on PVS. N Engl J Med 1994;330:1499-1508.

-13 Fins JJ, Master MG, Gerber LM, Giacino JT: The minimally conscious state: a diagnosis in search of an epidemiology. Arch Neurol 2007; 64:1400-1405.

14 Medical aspects of the persistent vegetative state (2). The Multi-Society Task Force on PVS. N Engl J Med 1994;330:1572-1579.

15 Rehabilitation of persons with traumatic brain injury. NIH Consens Statement 1998; 16:1-41.

16 Consensus conference. Rehabilitation of persons with traumatic brain injury. NIH Consensus Development Panel on Rehabilitation of Persons with Traumatic Brain Injury. JAMA 1999;282:974-983.

17 Borthwick C: Ethics and the vegetative state. Neuropsychol Rehabil 2005;15:257-263.
18 Italian Ministry of Healthcare: Study Group on Vegetative State. Final document. Rome 2009 (http://www.salute.gov.it/imgs/C_17_ pubblicazioni_1378_allegato.pdf).

19 Bates D: The vegetative state and the Royal College of Physicians guidance. Neuropsychol Rehabil 2005;15:175-183.

20 Saout V, Ombredane MP, Mouillie JM, Marteau C, Mathe JF, Richard I: Patients in a permanent vegetative state or minimally conscious state in the Maine-et-Loire county of France: a cross-sectional, descriptive study. Ann Phys Rehabil Med 2010;53:96-104.

21 Veronesi U: Italy: ad hoc committee on artificial nutrition and hydration of individuals in a permanent vegetative state. J Int Bioethique 2001;12:75-80.

22 Jennett B: The vegetative state. J Neurol Neurosurg Psychiatry 2002;73:355-357.

23 Strauss DJ, Shavelle RM, Ashwal S: Life expectancy and median survival time in the permanent vegetative state. Pediatr Neurol 1999;21: 626-631.

24 Kanno T, Morita I, Yamaguchi S, Yokoyama T, Kamei Y, Anil SM, Karagiozov KL: Dorsal column stimulation in persistent vegetative state. Neuromodulation 2009;12:33-38.

25 Liu JT, Tan WC, Liao WJ: Effects of electrical cervical spinal cord stimulation on cerebral blood perfusion, cerebrospinal fluid catecholamine levels, and oxidative stress in comatose patients. Acta Neurochir Suppl 2008;101:7176.

-26 Matsui T, Asano T, Takakura K, Yamada R, Hosobuchi Y: Beneficial effects of cervical spinal cord stimulation (cSCS) on patients with impaired consciousness: a preliminary report. Pacing Clin Electrophysiol 1989;12:718-725.

27 Kanno T, Kamel Y, Yokoyama T, Shoda M, Tanji H, Nomura M: Effects of dorsal column spinal cord stimulation (DCS) on reversibility of neuronal function - experience of treatment for vegetative states. Pacing Clin Electrophysiol 1989;12:733-738.

28 Fujii M, Sadamitsu D, Maekawa T, Uesugi S, Ozaki S, Koizumi H, Uetsuka S, Sakamoto K, Yamashita T, Ito H: Spinal cord stimulation therapy at an early stage for unresponsive patients with hypoxic encephalopathy. No Shinkei Geka 1998;26:315-321.

29 Kanno T, Kamei Y, Yokoyama T, Shoda M, Tanji H, Nomura M: Effects of neurostimulation on the reversibility of neuronal function: experience of treatment for vegetative status. No Shinkei Geka 1988;16:157-163.

30 Liu JT, Lee JK, Tyan YS, Liu CY, Chen YH, Lin TB: Neuromodulation on cervical spinal cord combined with hyperbaric oxygen in comatose patients - a preliminary report. Surg Neurol 2009;72(suppl 2):S28-S34; discussion S34-S35.

\section{$\checkmark 43$} Dossi RC: Neuronal activities in brain-stem
cholinergic nuclei related to tonic activation
processes in thalamocortical systems. J Neurosci 1990;10:2541-2559.

31 Yokoyama T, Kamei Y, Shoda M, Abe M, Onouchi K, Kasama A, Inoue T, Kanno T: Treatment of vegetative status with dorsum column stimulation. No Shinkei Geka 1990;18: $39-45$.

32 Momose T, Matsui T, Kosaka N, Ohtake T, Watanabe T, Nishikawa J, Abe K, Tanaka J, Takakura K, Iio M: Effect of cervical spinal cord stimulation (cSCS) on cerebral glucose metabolism and blood flow in a vegetative patient assessed by positron emission tomography (PET) and single photon emission computed tomography (SPECT). Radiat Med 1989;7:243-246.

33 Kuwata T: Effects of the cervical spinal cord stimulation on persistent vegetative syndrome: experimental and clinical study. No Shinkei Geka 1993;21:325-331.

34 Ainslie PN, Ogoh S: Regulation of cerebral blood flow in mammals during chronic hypoxia: a matter of balance. Exp Physiol 2010; 95:251-262.

35 Barolat G, Myklebust JB, Wenninger W: Effects of spinal cord stimulation on spasticity and spasms secondary to myelopathy. Appl Neurophysiol 1988;51:29-44.

36 Barolat-Romana G, Myklebust JB, Hemmy DC, Myklebust B, Wenninger W: Immediate effects of spinal cord stimulation in spinal spasticity. J Neurosurg 1985;62:558-562.

37 Laureys S, Antoine S, Boly M, Elincx S, Faymonville ME, Berre J, Sadzot B, Ferring M, De Tiege X, van Bogaert P, Hansen I, Damas P, Mavroudakis N, Lambermont B, Del Fiore G, Aerts J, Degueldre C, Phillips C, Franck G, Vincent JL, Lamy M, Luxen A, Moonen G, Goldman S, Maquet P: Brain function in the vegetative state. Acta Neurol Belg 2002;102: 177-185.

38 Laureys S, Owen AM, Schiff ND: Brain function in coma, vegetative state, and related disorders. Lancet Neurol 2004;3:537-546.

39 McDonagh MS, Morgan D, Carson S, Russman BS: Systematic review of hyperbaric oxygen therapy for cerebral palsy: the state of the evidence. Dev Med Child Neurol 2007;49: 942-947.

40 Fuller PM, Sherman D, Pedersen NP, Saper $\mathrm{CB}, \mathrm{Lu}$ J: Reassessment of the structural basis of the ascending arousal system. J Comp Neurol 2011;519:933-956.

41 Lee MG, Hassani OK, Alonso A, Jones BE: Cholinergic basal forebrain neurons burst with theta during waking and paradoxical sleep. J Neurosci 2005;25:4365-4369.

42 Visocchi M, Tartaglione T, Romani R, Meglio M: Spinal cord stimulation prevents the effects of combined experimental ischemic and traumatic brain injury. An MR study. Stereotact Funct Neurosurg 2001;76:276-281. 
-44 Robinson FR, Rice PM, Holleman JR, Berger TW: Projection of the magnocellular red nucleus to the region of the accessory abducens nucleus in the rabbit. Neurobiol Learn Mem 2001;76:358-374.

-45 Van Der Werf YD, Sadikot AF, Strafella AP, Paus T: The neural response to transcranial magnetic stimulation of the human motor cortex. II. Thalamocortical contributions. Exp Brain Res 2006;175:246-255.

46 Fuster JM, Uyeda AA: Reactivity of limbic neurons of the monkey to appetitive and aversive signals. Electroencephalogr Clin Neurophysiol 1971;30:281-293.

47 Visocchi M: Neuromodulation of cerebral blood flow by spinal cord electrical stimulation: the role of the Italian school and state of art. J Neurosurg Sci 2008;52:41-47.

-48 Visocchi M, Argiolas L, Meglio M, Cioni B, Basso PD, Rollo M, Cabezas D: Spinal cord stimulation and early experimental cerebral spasm: the 'functional monitoring' and the 'preventing effect'. Acta Neurochir (Wien) 2001;143:177-185.

-49 Visocchi M, Cioni B, Pentimalli L, Meglio M Increase of cerebral blood flow and improvement of brain motor control following spinal cord stimulation in ischemic spastic hemiparesis. Stereotact Funct Neurosurg 1994;62: 103-107.

-50 Visocchi M, Cioni B, Vergari S, Marano G, Pentimalli L, Meglio M: Spinal cord stimulation and cerebral blood flow: an experimental study. Stereotact Funct Neurosurg 1994;62: 186-190.

51 Meglio M, Cioni B, Visocchi M: Cerebral hemodynamics during spinal cord stimulation. Pacing Clin Electrophysiol 1991;14:127-130.

- 52 Meglio M, Cioni B, Visocchi M, Nobili F, Rodriguez G, Rosadini G, Chiappini F, Sandric S: Spinal cord stimulation and cerebral haemodynamics. Acta Neurochir (Wien) 1991; 111:43-48.

53 De Andrés J, Tatay J, Revert A, Valia JC, Villanueva $\mathrm{V}$ : The beneficial effect of spinal cord stimulation in a patient with severe cerebral ischemia and upper extremity ischemic pain. Pain Pract 2007;7:135-142.

54 Visocchi M, Giordano A, Calcagni M, Cioni B, Di Rocco F, Meglio M: Spinal cord stimulation and cerebral blood flow in stroke: personal experience. Stereotact Funct Neurosurg 2001;76:262-268.

55 Clavo B, Robaina F, Catala L, Lloret M, Pinar B, Carames MA, Ruiz A, Cabezon A, Gonzalez G, Lara P, Ruiz-Egea E, Hernandez MA: Cerebral blood flow increase in cancer patients by applying cervical spinal cord stimulation. Neurocirugia (Astur) 2007;18:28-32; discussion 33-35.

56 Clavo B, Robaina F, Montz R, Domper M, Carames MA, Morera J, Pinar B, Hernandez MA, Santullano V, Carreras JL: Modification of glucose metabolism in brain tumors by using cervical spinal cord stimulation. J Neurosurg 2006;104:537-541.
7 Clavo B, Robaina F, Catala L, Perez JL, Lloret M, Carames MA, Morera J, Lopez L, Suarez G, Macias D, Rivero J, Hernandez MA: Effect of cervical spinal cord stimulation on regional blood flow and oxygenation in advanced head and neck tumours. Ann Oncol 2004;15:802807.

58 Robaina F, Clavo B, Catala L, Carames MA, Morera J: Blood flow increase by cervical spinal cord stimulation in middle cerebral and common carotid arteries. Neuromodulation 2004;7:26-31.

59 Clavo B, Robaina F, Catala L, Valcarcel B, Morera J, Carames MA, Ruiz-Egea E, Panero F, Lloret M, Hernandez MA: Increased locoregional blood flow in brain tumors after cervical spinal cord stimulation. J Neurosurg 2003;98:1263-1270.

60 Clavo B, Robaina F, Morera J, Ruiz-Egea E, Perez JL, Macias D, Carames MA, Catala L, Hernandez MA, Gunderoth M: Increase of brain tumor oxygenation during cervical spinal cord stimulation. Report of three cases. J Neurosurg 2002;96:94-100.

61 Takanashi Y, Shinonaga M: Spinal cord stimulation for cerebral vasospasm as prophylaxis. Neurol Med Chir (Tokyo) 2000;40:352-356; discussion 356-357.

62 Clavo B, Robaina F, Montz R, Carames MA, Lloret M, Ponce P, Hernandez MA, Carreras JL: Modification of glucose metabolism in radiation-induced brain injury areas using cervical spinal cord stimulation. Acta Neurochir (Wien) 2009;151:1419-1425

63 Robaina F, Clavo B: Spinal cord stimulation in the treatment of post-stroke patients: current state and future directions. Acta Neurochir Suppl 2007;97:277-282.

64 Mazzone P, Pisani R, Pizio N, Arrigo A, Nobili F: Cerebral blood flow and somatosensory evoked response changes induced by spinal cord stimulation: preliminary follow-up observations. Stereotact Funct Neurosurg 1994; 62:179-185.

65 Clavo B, Robaina F, Valcarcel B, Catala L, Perez JL, Cabezon A, Jorge IJ, Fiuza D, Hernandez MA, Jover R, Carreras JL: Modification of loco-regional microenvironment in brain tumors by spinal cord stimulation. Implications for radio-chemotherapy. J Neurooncol 2012; 106:177-184.

66 Fontanella M, Valfre W, Benech F, Carlino C, Garbossa D, Ferrio M, Perez R, Berardino M, Bradac G, Ducati A: Vasospasm after SAH due to aneurysm rupture of the anterior circle of Willis: value of TCD monitoring. Neurol Res 2008;30:256-261.

67 Pagni CA, Fontanella M, Cossandi C, Griva F, Zullo N, Bradac GB: Therapeutic decisions and grading of subarachnoid hemorrhage. Minerva Anestesiol 1998;64:159-162.

68 Visocchi M: Spinal cord stimulation and cerebral haemodynamics. Acta Neurochir Suppl 2006;99:111-116.
69 Mazzone P, Pisani R, Nobili F, Arrigo A, Gambaro M, Rodriguez G: Assessment of regional cerebral blood flow during spinal cord stimulation in humans. Stereotact Funct Neurosurg 1995;64:197-201.

70 Myklebust JB, Cusick JF, Boerboom LE, Prieto TE, Khan TA: Vascular effects of spinal cord stimulation in the monkey. Stereotact Funct Neurosurg 1995;64:32-39.

71 Isono M, Kaga A, Fujiki M, Mori T, Hori S: Effect of spinal cord stimulation on cerebral blood flow in cats. Stereotact Funct Neurosurg 1995;64:40-46.

72 Patel S, Huang DL, Sagher O: Evidence for a central pathway in the cerebrovascular effects of spinal cord stimulation. Neurosurgery 2004;55:201-206; discussion 206.

73 Patel S, Huang DL, Sagher O: Sympathetic mechanisms in cerebral blood flow alterations induced by spinal cord stimulation. J Neurosurg 2003;99:754-761.

74 Hosobuchi Y: Treatment of cerebral ischemia with electrical stimulation of the cervical spinal cord. Pacing Clin Electrophysiol 1991;14 122-126.

75 Hosobuchi Y: Electrical stimulation of the cervical spinal cord increases cerebral blood flow in humans. Appl Neurophysiol 1985;48: 372-376.

76 Wu M, Komori N, Qin C, Farber JP, Linderoth $\mathrm{B}$, Foreman RD: Roles of peripheral terminals of transient receptor potential vanilloid-1 containing sensory fibers in spinal cord stimulation-induced peripheral vasodilation. Brain Res 2007;1156:80-92.

77 Wu M, Qin C, Foreman RD, Farber JP: Transient receptor potential vanilloid receptor-1 does not contribute to slowly adapting airway receptor activation by inhaled ammonia. Auton Neurosci 2007;133:121-127.

78 Yang X, Farber JP, Wu M, Foreman RD, Qin $\mathrm{C}$ : Roles of dorsal column pathway and transient receptor potential vanilloid type 1 in augmentation of cerebral blood flow by upper cervical spinal cord stimulation in rats. Neuroscience 2008;152:950-958.

79 Tanaka S, Barron KW, Chandler MJ, Linderoth B, Foreman RD: Low intensity spinal cord stimulation may induce cutaneous vasodilation via CGRP release. Brain Res 2001; 896:183-187.

80 Visocchi M, Di Rocco F, Meglio M: Protective effect of spinal cord stimulation on experimental early cerebral vasospasm. Conclusive results. Stereotact Funct Neurosurg 2001;76: 269-275.

81 Meglio M, Cioni B, Rossi GF, Sandric S, Santarelli P: Spinal cord stimulation affects the central mechanisms of regulation of heart rate. Appl Neurophysiol 1986;49:139-146.

82 Visocchi M, Chiappini F, Cioni B, Meglio M: Cerebral blood flow velocities and trigeminal ganglion stimulation. A transcranial Doppler study. Stereotact Funct Neurosurg 1996;66: 184-192. 